\title{
Infrared imaging of Venus from IRTF/ProtoCAM observations in 1991
}

\author{
Y. Roos-Serote, ${ }^{1 *}$ V. Coupé, ${ }^{2}$ P. Drossart, ${ }^{1}$ E. Lellouch, ${ }^{\prime}$ O. Saint-Pé' and Th. Encrenaz \\ DESPA. Observatoire de Paris-Meudon, 5 Place Jules Janssen, 92195 Meudon Cedex. France \\ Sterrewacht Leiden. Postbus 9513. 2300 RA Leiden. The Netherlands
}

Received IS July 1995; revised 10 November 1995; accepted 15 November 1995

\begin{abstract}
Infrared observations of Venus' night-side between 3 and $5 \mu \mathrm{m}$ provide a valuable means to study the upper cloud structure (at approximately $68 \mathrm{~km}$ ) and the thermal structure above the clouds. New observations between 3.67 and $5.08 \mu \mathrm{m}$, concerning spectral images of Venus obtained in October 1991 with the ProtoCAM/IRTF and a Circular Variable Filter, are presented. A cloud particle scale height for the upper clouds of $3.9 \pm 1 \mathrm{~km}$ is retrieved from limb darkening measurements, which is in good agreement with measurements from both space probes and Earthbased observatories. The observations show an increase in temperature from the centre towards the poles when sounding altitudes above $72 \mathrm{~km}$. This, along with temperatures at cloud top levels, implies isothermal profiles between 68 and $74 \mathrm{~km}$ at high latitudes. Copyright (C) 1996 Elsevier Science Ltd
\end{abstract}

\section{Introduction}

The night-side emission of the cloud deck of Venus hals been studied in the infrared by various authors. Diner (1978) recorded spectra from the night-side at wavelengths between 8 and $20 \mu \mathrm{m}$. He made use of limb darkening measurements and a simplified radiative transfer model in order to deduce a cloud particle scale height of the upper clouds. The same type of analysis has been performed by Taylor et al. (1980) with Pioneer-Venus data. During the Galileo/Venus encounter in February 1990, the Near Infrared Mapping Spectrometer (spectral range 0.7 $5.2 \mu \mathrm{m}$ ) provided new information on the composition of Venus' atmosphere and the cloud structure (Carlson et al., 1991). The data allowed limb darkening measurements in the $3-5 \mu \mathrm{m}$ range (Roos et al., 1993) and the retrieval of the thermal profile above the clouds (Roos-Serote $e t$ (dl. 1995)

Correspondenie w: M. Roos-Serote
Infrared observations of the upper clouds have provided a very stable picture with time. In this context, the results presented in this paper contribute to the confirmation of this constant behaviour.

In the next section we will discuss the observations and the absolute calibration. Section 3 will be devoted to the presentation and the discussion of the results. The conclusions are presented in the last section.

\section{Observations and data reduction}

The data were obtained at the InfraRed Telescope Facility (IRTF) at Mauna Kea. Hawaii, with the ProtoCAM instrument and a Circular Variable Filter. ProtoCAM is an infrared camera with a CCD of $58 \times 60$ pixels. Spectral images were recorded at 29 wavelengths, between 3.673 and $4.156 \mu \mathrm{m}$ on 12 October 1991 and between 4.654 and $5.084 \mu \mathrm{m}$ on 16 October 1991 . The spectral resolving power is of the order of 60 and the spatial resolution is 0.35 aresec pix ${ }^{\prime}$ corresponding to $140 \mathrm{~km}$ pix or about I pix 'Venus coordinates at the sub-Earth point. Venus had a phase of about 0.38 at the time of the observation. (phase angle about 100 ), so that a large part of the nightside of the planet was observable. The images of 12 October mainly show the northern hemisphere. The images of 16 October consist of two sequences, one showing the northern hemisphere and the other the southern hemisphere. Figure 1 displays two images at two different wavelengths for 12 October. We followed a standard reduction procedure. i.e. subtraction of the sky from the raw data and division by flat fields.

An absolute flux calibration of the Venus images has been performed. Star images at the same dates and wavelengths as the Venus images were available (HR3826 and HR3547 for 12 and 16 October 1991. respectively). After calibration of the Venus images with the stars, spectra were extracted and compared to Galileo NIMS spectra at the same latitudes and with the same emission angle (201, 2-(04 and 2-(07 in Table 1. Drossart et al. (1993)). 
Table 1. Limb darkening measurements

\begin{tabular}{lccc}
\hline Authors & $T_{1}(\mathrm{~K})$ & $C(\mathrm{~K})$ & $H_{\text {cloud }}(\mathrm{km})$ \\
\hline Diner (1978) & - & 13.5 & 4.5 \\
Roos et al. (1993) & $236 \pm 1.8$ & $11.7 \pm 1$ & $4.1 \pm 0.6$ \\
This work & $233 \pm 1.4$ & $11.3 \pm 1.8$ & $3.9 \pm 1.0$ \\
\hline
\end{tabular}

This comparison showed that the shape of the calibrated ProtoCAM spectra corresponds very well to the NIMS spectra, but that the radiances are systematically too high. The difference, averaged over wavelength and latitude, is a factor of $2.45 \pm 0.3$ for 12 October and $2.41 \pm 0.3$ for 16 October. Because these two factors are the same for the two different series of images, with two different reference stars, a systematic error is implied. Possible causes might lie in the comparison of a point source to an extended source and/or in differences in air mass between the images of Venus and those of the reference stars. However, this last hypothesis has been verified to reduce the factors by about $25 \%$ only.

It was decided to scale the star-calibrated ProtoCAM radiances to the NIMS radiances, using the factors found by the comparison of three ProtoCAM spectra to three similar NIMS spectra, as discussed above. The reason that we prefer the absolute calibration of the Galileo/NIMS spectra, dating 20 months earlicr, over the reference stars, is that a comparison of the Galileo/NIMS data (Roos et $a l ., 1993$ ) with the Pioneer-Venus data (Taylor et al., 1980) shows very similar brightness temperatures, indicating that larger scale temporal variations of the absolute flux are unlikely.

Combining all the uncertainties $(\mathrm{S} / \mathrm{N}$, absolute infrared flux calibration for the stars, the rescaling to the Galileo/NIMS spectra) it is estimated that the error on the intensity is on the order of $17 \%$. When the intensity is converted to blackbody temperatures, this error implies an uncertainty of $3 \mathrm{~K}$ on these temperatures.

Figure 2 shows two spectra at different latitudes, extracted from the images, compared to Galileo/NIMS spectra. The continuum is formed by emission from the upper clouds with a unit cloud optical depth at about $68 \mathrm{~km}$ altitude, and superimposed are two $\mathrm{CO}_{2}$ bands at $4.3 \mu \mathrm{m}\left(v_{3}\right)$ and at $4.8 \mu \mathrm{m}\left(v_{1}+v_{2}\right)$. No data were obtained in the centre of the $4.3 \mu \mathrm{m} \mathrm{CO} \mathrm{CO}_{3}$ band, because of the strong absorption by terrestrial $\mathrm{CO}_{2}$.

\section{Results and discussion}

\subsection{Limb darkening}

From the calibrated and Galileo/NIMS-corrected images, limb darkening measuments have been performed at three different continuum wavelengths $(3.698,3.989$ and $4.950 \mu \mathrm{m})$ in the equatorial region $(-25,+25)$, in order to derive a value for the cloud particle scale height. An approximative radiative transfer model without scattering has been used to derive the following equation (Diner, 1978: Roos et al., 1993):

$$
T(\mu)=T_{1}+C \times \ln (\mu)
$$

where $C=-(\mathrm{d} T / \mathrm{d} z) \times H_{\text {choud }}, T$ is the brightness temperature. $\mu$ the cosine of the emission angle, $\mathrm{d} T / \mathrm{d} z$ the thermal gradient and $H_{\text {cloud }}$ the cloud particle scale height. This model has been used by Diner (1978) for limb darkening measurements of Venus' night-side $(820 \mu \mathrm{m})$ and by Roos et al. (1993) for measurements in the same spectral region as in this work, covering the same latitudes. using Galileo/NIMS data. Figure 3 shows two typical examples of limb darkening curves. The linear dependence on $\ln (\mu)$ is obvious from this figure. In total, $13 \operatorname{limb}$ darkening curves have been measured, and the mean value for the parametres $C$ and $T_{1}$ are found to be $11.3 \pm 1.8 \mathrm{~K}$ and $233 \pm 1.4 \mathrm{~K}$, respectively. The error bars correspond to the $1 \sigma$ variation about the mean value. It has been checked that the effect of scaling the images to NIMS radiances, as explained in the previous section, is only about $10 \%$ on the value of $C$. This is about two-thirds of the variation around the mean value and it means that the determination of the value of $C$ can be considered independent of the calibration problem. The effect for $T_{1}$ is about $6 \%$, or about $14 \mathrm{~K}$.

Assuming the same thermal gradient at $68 \mathrm{~km}$ altitude as used by Roos et al. (1993), i.e. $-2.9 \pm 0.4 \mathrm{~K} \mathrm{~km}^{-1}$ (Venus International Reference Atmosphere model (Seiff et al., 1985)), a value for $I_{\text {cloud }}$ of $3.9 \pm 1 \mathrm{~km}$ is derived (the gas scale height at $68 \mathrm{~km}$ altitude is about $5 \mathrm{~km}$ (Schubert, 1983)). It has been shown by Roos et al. (1993) that the accuracy of this simplified model is satisfactory for the determination of the cloud particle scale height. Full scattering calculations (Grinspoon et al., 1993; Roos et al., 1993) result in an augmentation of the value of the cloud particle scale height by about $1 \mathrm{~km}$, which is within the range of the uncertainty. Table 1 summarizes the results and confirms that they correspond well to values found earlier.

As has been discussed by Roos et al. (1993). the parameter $T_{1}$ gives an indication of the cloud temperature. In view of the absolute calibration problem encountered with the ProtoCAM data, the obtained values of $T_{1}$ are not reliable enough to allow a detailed analysis.

\subsection{The high latitude regions}

We will now discuss the variations in thermal structure as a function of latitude that can be observed above the cloud tops in the infrared. Figure 1 shows two images, one at $3.673 \mu \mathrm{m}$, the cloud top continuum. and another at $4.217 \mu \mathrm{m}$, in the bluc wing of the $4.3 \mu \mathrm{m} \mathrm{CO} \mathrm{CO}_{2} v_{3}$ band. As can be seen in the second image, the intensity increases relative to the intensity at the equator, with increasing latitude. This effect is essentially due to a change in thermal structure to a (quasi-) isothermal atmosphere above the cloud tops in the northern and southern hemisphere (around -55 and $+60^{\circ}$ ). This has been observed before : Taylor et al. (1980) and Seiff (1983) found from PioneerVenus data isothermal profiles between 60 and $80 \mathrm{~km}$ altitude at latitudes +65 and -52 (Seiff, 1983. Fig. 17). with a temperature of about $230 \mathrm{~K}$. Furthermore. Dubois et al. (1990) observed inversion structures and quasi-iso- 


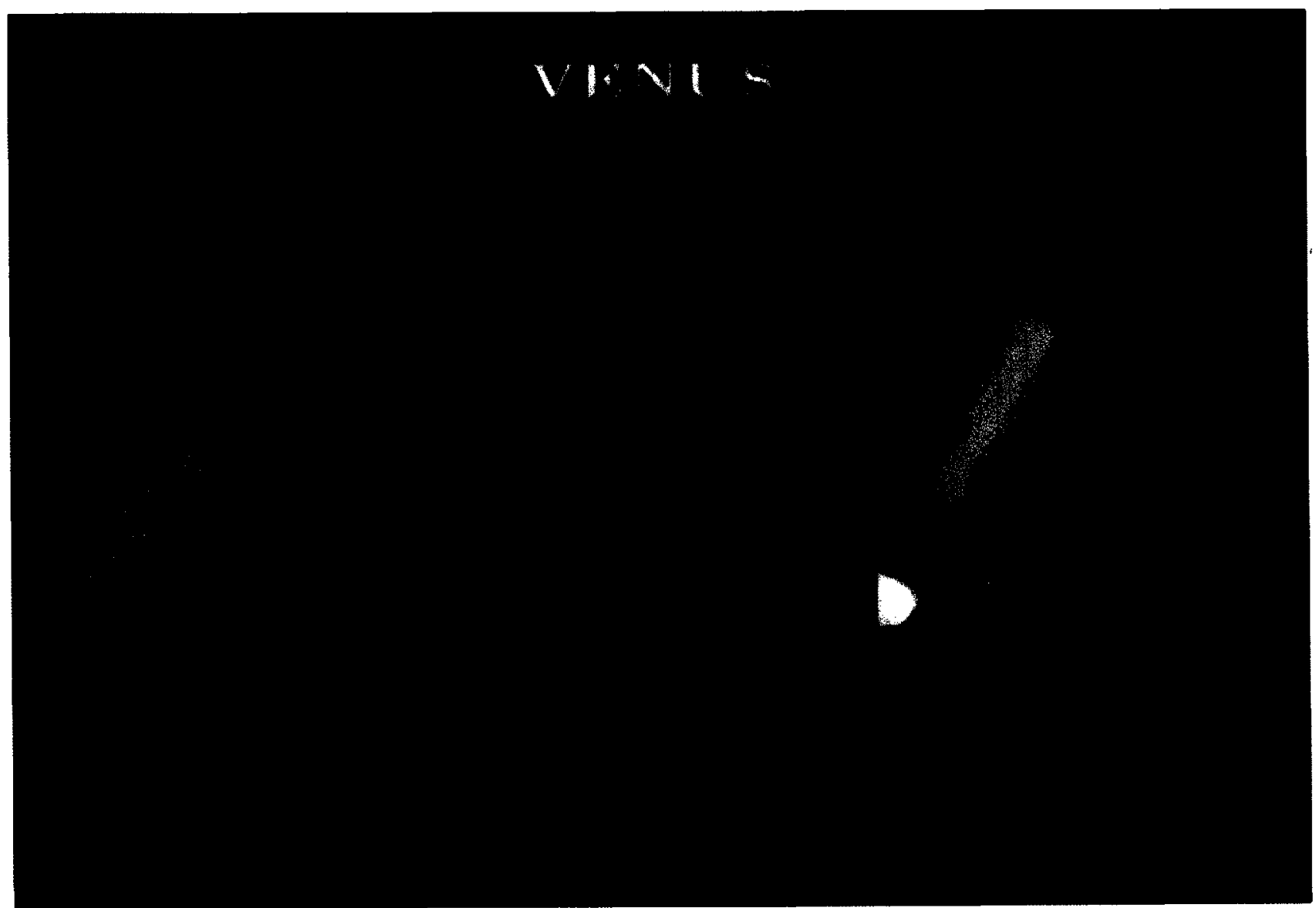

Fig. 1. Two images of 12 October 1991. Spatial resolution is $140 \mathrm{~km}$ pix 'at the centre of the disk (emission angle zero). The left image shows the cloud top continuum at $68 \mathrm{~km}$ altitude $(3.673 \mu \mathrm{m})$. The right one is at $4.217 \mu \mathrm{m}$. in the blue wing of the $4.3 \mu \mathrm{m} \mathrm{CO}, 1 ;$ band. and sounds some $6 \mathrm{~km}$ higher. A warmer high latitude region is clearly present. Indicated north and cast refer to venus 

(a)

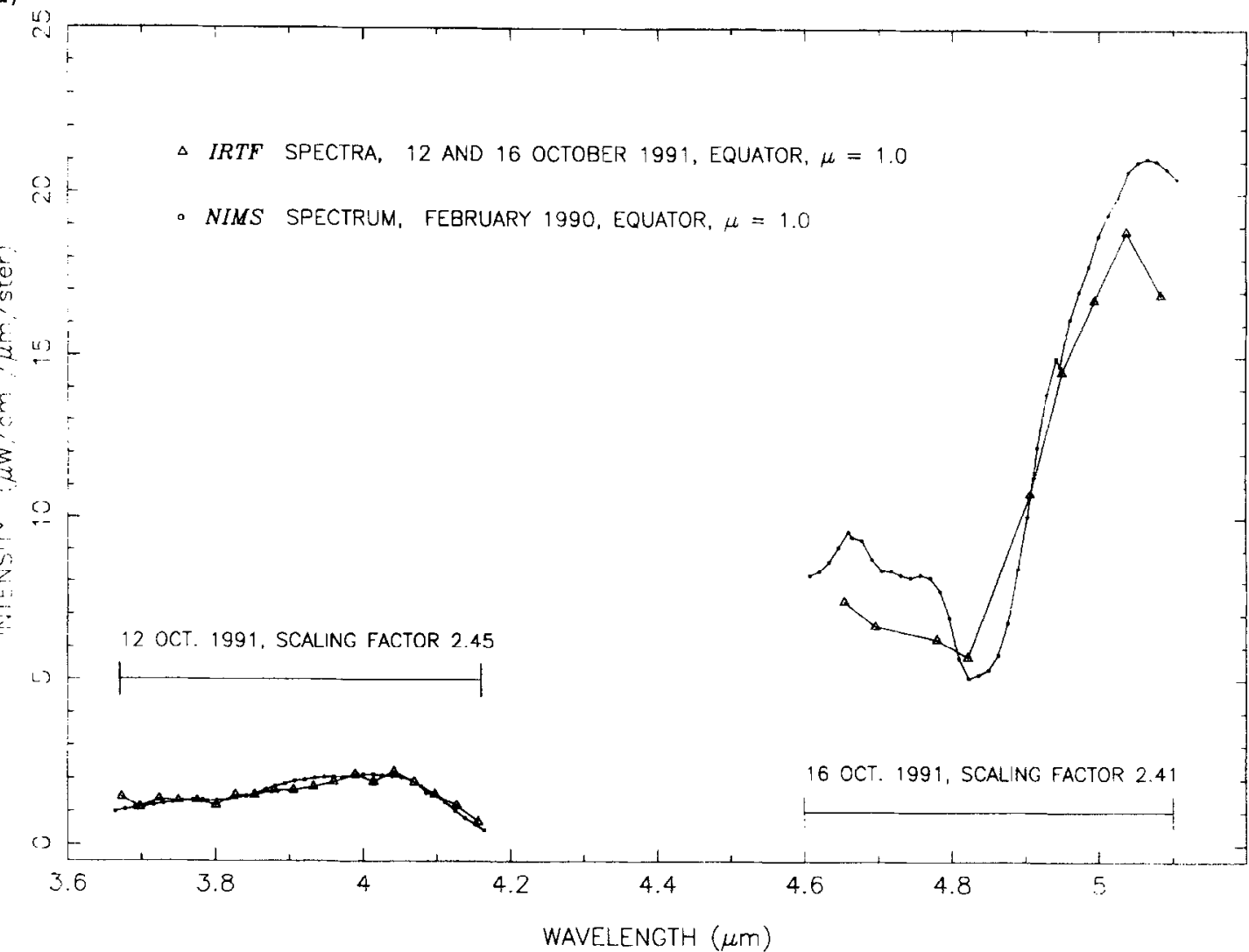

(b)

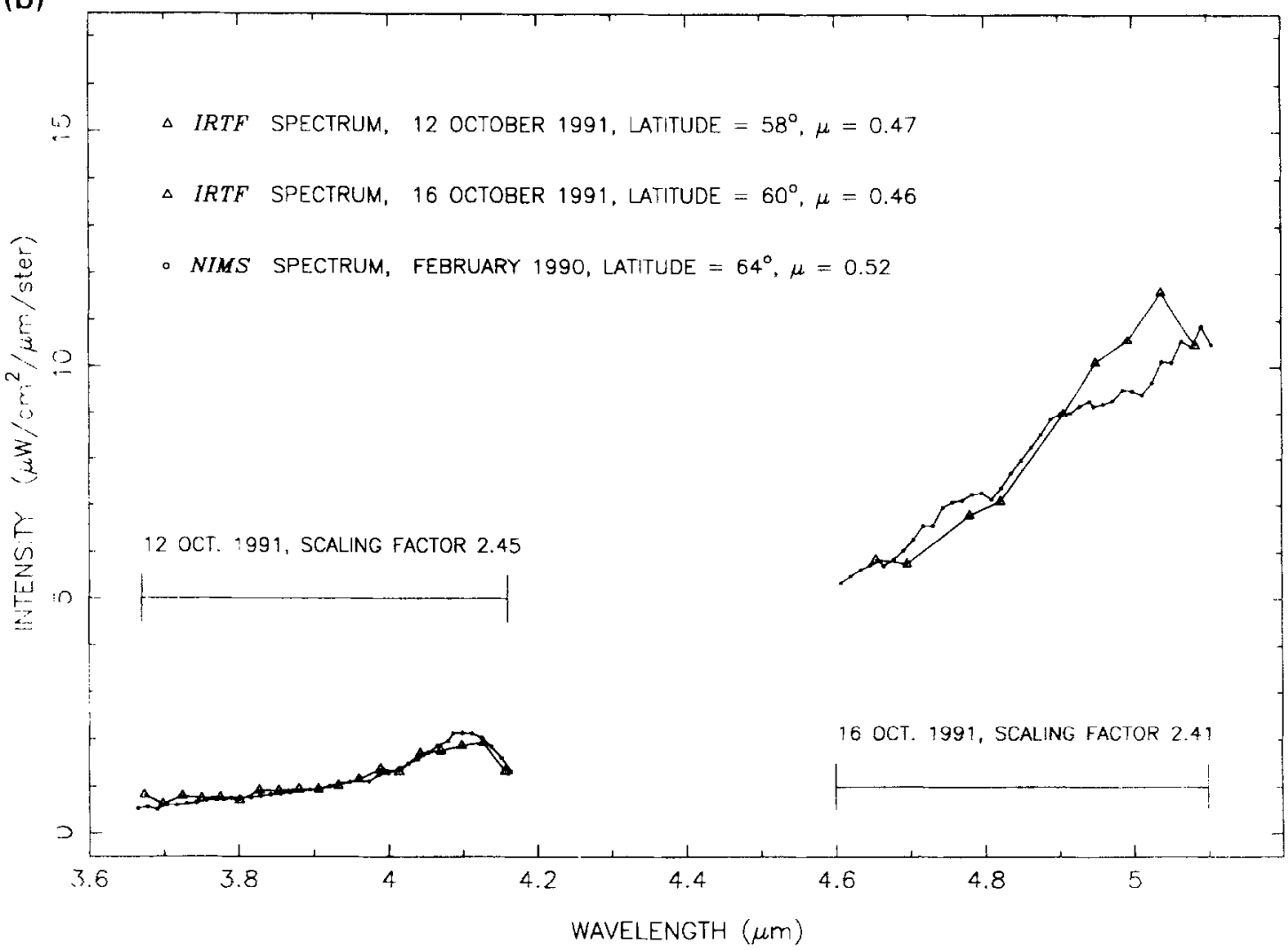

Fig. 2. (a) A spectrum at the equator (emission angle 0 ). combining two observation runs of two different nights, in order to cover the different wavelength regions. The spectra are scaled relative to the corresponding Galileo/NIMS spectrum (Table 1, 2-(7). Diossalt $e t$ al., 1993), as explained in the text. (b) A spectrum at high latitude (emission angle 62), same as (a) (Galileo/NIMS spectrum. Table 1. 2-01. Drossart 't al. 1993). As can be seen, both CO absorption features $\left(v_{3}\right.$ and $\left.r_{1}+r_{2}\right)$ have drastically changed, indicating an isothermal atmosphere around $70 \mathrm{~km}$ 


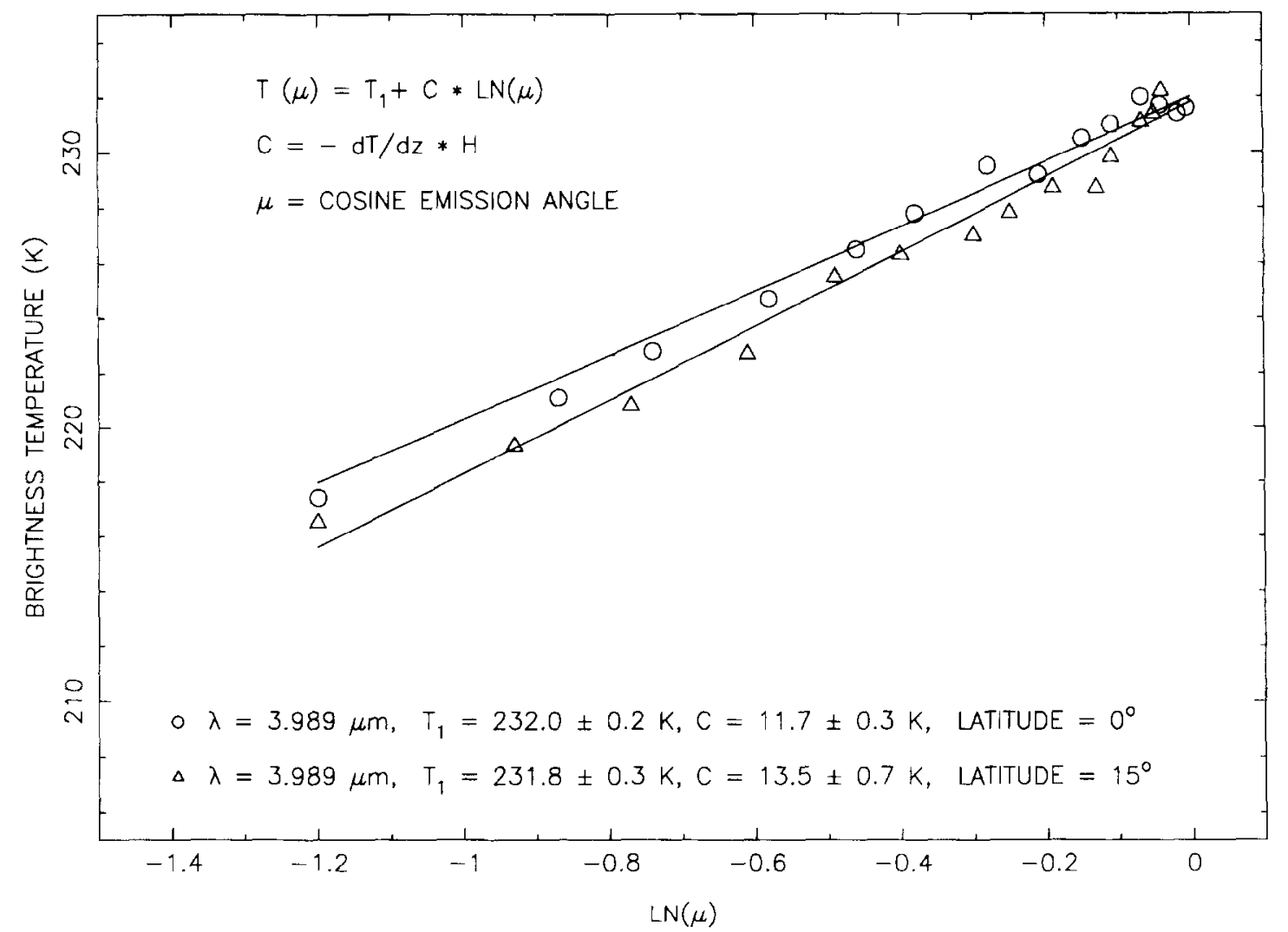

Fig. 3. Two limb darkening measurements from the image at $3.989 \mu \mathrm{m}$ (12 October 1991), at the equator and at 15 latitude. The line shows the fit as obtained by the model (equation (1), see text). The derived model parameters $T_{1}$ and $C$ are shown in the figure. Note the clear linear dependence of the data with $\ln \mu$, where $\mu$ is the cosine of the emission angle. Brightness temperature corresponds to a blackbody temperature at $3.989 \mu \mathrm{m}$ and the intensity as measured from the image

thermal profiles between about 64 and $75 \mathrm{~km}$ altitude at $+60^{\circ} \pm 5$ latitude in Venera-15 data, also at a temperature around $230 \mathrm{~K}$.

In previous papers the spectrum of Venus in the $3-5 \mu \mathrm{m}$ region has been modelled, using a non-scattering band model (Roos e't al., 1993; Roos-Serote et al., 1995). This model was used here in order to calculate the intensity and the effective altitude (defined as the altitude where the weighting function in the radiative transfer equation peaks) at a given wavelength, assuming that the thermal structure in the northern hemisphere is described by the Venus International Reference Atmosphere model (Seiff et al., 1985) at the appropriate latitudes.

Going from the continuum to the centre of the $4.3 \mu \mathrm{m}$
$\mathrm{CO}_{2} v_{3}$ absorption band, altitudes from 68 up to $90 \mathrm{~km}$ are sounded. Since the absorption is very strong in the centre of the band, this part of the spectrum is unobservable from the Earth, because of absorption by terrestrial $\mathrm{CO}_{2}$. However, observations were done on the bluc wing of this band and in the $4.8 \mu \mathrm{m} \mathrm{CO} v_{1}+v_{2}$ band. which is a weak absorption structure.

Two wavelengths were selected, one in the blue wing of the $\mathrm{CO}, v_{3}$ band at $4.098 \mu \mathrm{m}$ for 12 October and another in the centre of the $\mathrm{CO}_{2} \mathrm{r}_{1}+\mathrm{r}_{2}$ band at $4.822 \mu \mathrm{m}$ for 16 October. At both these wavelengths altitudes of about $72 \mathrm{~km}$ at the equator are sounded, i.e. about $4 \mathrm{~km}$ above the cloud top level. They both show evidence for a warmer atmosphere relative to the equator at high latitudes

Fig. 4. (a) A cut at constant longitude showing the difference in brightness temperature as measured at 4.950 (continuum) and $4.822 \mu \mathrm{m}\left(\mathrm{CO}_{2} v_{1}+v_{2}\right)$ for 16 October 1991 (error bars indicate the $1-\sigma$, error of $3 \mathrm{~K}$ on the temperatures). The sounded altitudes range from $68 \mathrm{~km}$ at the equator to $71 \mathrm{~km}$ at \pm 65 latitude at $4.950 \mu \mathrm{m}$ and from 72 to $74 \mathrm{~km}$ respectively at $4.822 \mu \mathrm{m}$. For comparison, the results of a synthetic calculation using the Venus International Reference Atmosphere model as thermal structure for the northern hemisphere are shown and found to reproduce well the general trend of the curves (see text for more details). (b) A cut at constant longitude for 12 October 1991 (northern hemisphere only). At the continuum wavelength $(3.698 \mu \mathrm{m})$ the sounded altitudes range from $68 \mathrm{~km}$ at the equator to $71 \mathrm{~km}$ at +65 and in the blue wing of the $4.3 \mu \mathrm{m} \mathrm{CO}_{2} \mathrm{v}_{3}$ band $(4.098 \mu \mathrm{m})$ these values are 72 and $74 \mathrm{~km}$, respectively (error bars indicate the $1-\sigma$, error of $3 \mathrm{~K}$ on the temperatures). For comparison, the results of a synthetic calculation using the Venus International Reference Atmosphere model as thermal structure for the northern hemisphere are shown and found to reproduce well the general trend of the curves (see text for more details) 
(a)

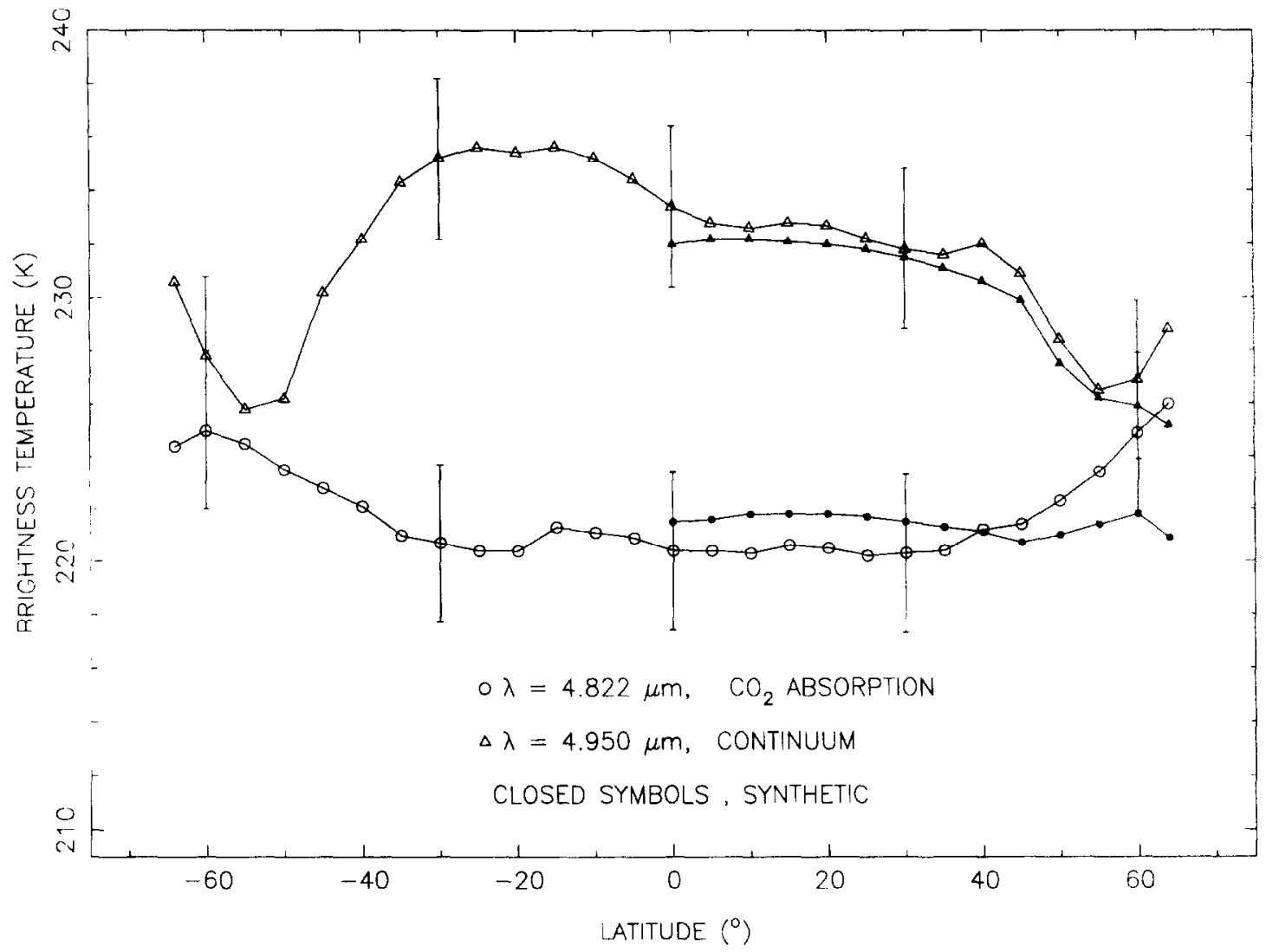

(b)

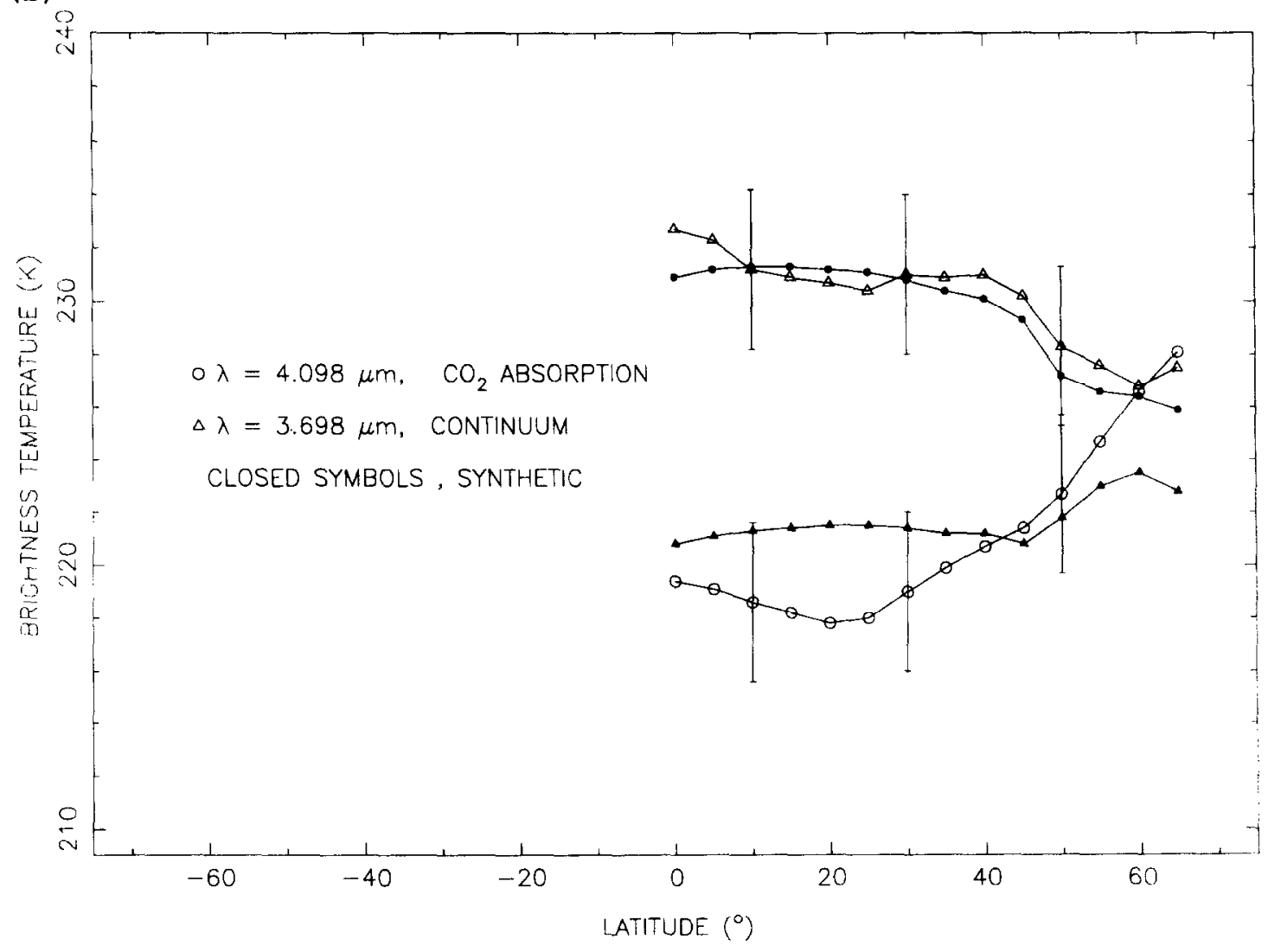


(northern hemisphere for 12 October, and both hemispheres for 16 October). Note that at high latitudes emission angles are large, so that still higher effective levels of up to $74 \mathrm{~km}$ are sounded at the wavelengths in the $\mathrm{CO}_{2}$ bands and up to about $71 \mathrm{~km}$ at continuum wavelengths.

When comparing brightness temperatures at the $\mathrm{CO}_{2}$ band wavelengths to brightness temperatures measured at continuum wavelengths, the general trend is that both tempcratures approach each other at latitudes around \pm 60 . This implies a change in thermal gradient towards an isothermal atmosphere. It can also be clearly seen in the spectrum of the northern region (Fig. 2b). The $4.8 \mu \mathrm{m}$ $\mathrm{CO}_{2} v_{1}+v_{2}$ absorption feature has disappeared and the region of the spectrum around $4.1 \mu \mathrm{m}$ (the beginning of the $4.3 \mu \mathrm{m} \mathrm{CO}_{2} v_{3}$ band) has risen, indicating an isothermal atmosphere in the $7 \mathrm{l}-74 \mathrm{~km}$ altitude region (emission angle is 62 for this spectrum).

Due to the absolute calibration problem it is impossible to assess absolute values for the temperatures from the ProtoCAM data. However, the relative variation of the brightness temperatures with latitude is well determined. In Figs 4a and b two cuts at constant longitude (relative to the central meridian) are shown and compared to synthetic calculations with the band model and the VIRA thermal structure mentioned above. Figure 4 a shows the brightness temperature at 4.950 (continuum) and $4.822 \mu \mathrm{m}\left(\mathrm{CO}_{2} v_{1}+v_{2}\right)$ for 16 October. The sounded altitudes range from about $68 \mathrm{~km}$ at the equator to about $71 \mathrm{~km}$ at \pm 65 latitude for the continuum wavelength. In the $\mathrm{CO}_{2}$ band these numbers are 72 and $74 \mathrm{~km}$. The effect of a decreasing thermal gradient towards high latitude regions is clear in both hemispheres, with a minimum occurring near +60 in the northern hemisphere and at $-55^{\circ}$ in the southern hemisphere. Figure $4 \mathrm{~b}$ shows the brightness temperatures at $3.698 \mu \mathrm{m}$ (continuum, effective altitude ranges from $68 \mathrm{~km}$ at the equator to $71 \mathrm{~km} \mathrm{at}$ +65 latitude $)$ and $4.098 \mu \mathrm{m}\left(\mathrm{CO}_{2} v_{3}\right.$, effective altitude ranges from 72 to $74 \mathrm{~km}$ ) for 12 Octobcr. The synthetic calculations compare fairly well with the observations in that the general form of the brightness temperature versus latitude curves is reproduced. We have interpolated between the three available VIRA models at 0.45 and 60 latitude to obtain the thermal structure at any given latitude and we have fitted the continuum level by adjusting the altitude of unit cloud optical depth. The cloud had a scale height of $3.9 \mathrm{~km}$, as determined from the limb darkening measurements presented in the previous section.

The most important difference is that the calculations do not reproduce the increase in brightness temperature observed at continuum wavelengths for latitudes higher than about +55 and lower than -55 . This can be very well due to changes in the thermal structure relative to VIRA. which are known to exist for altitudes between 70 and $90 \mathrm{~km}$ (Roos-Serote et al.. 1995).

\section{Conclusions}

Earth-based observations in the near infrared of the nightside of Venus, as have been presented here, do provide a valuable means to study the cloud structure and the thermal structure above the clouds. In the present work the data were acquired by the ProtoCAM instrument at the IRTF facility (Hawaii). They are of good quality and permit a spatial and spectral study at the same time. Limb darkening measurements in the equatorial region are in good agreement with measurements from both space probes and Earth-based observatories and confirm the temporal stability of the cloud structure at infrared wavelengths. A cloud particle scale height of $3.9 \pm 1 \mathrm{~km}$ is derived for the upper clouds from limb darkening measurements, assuming VIRA temperature profile.

Further. warm high latitude regions show up in the images at wavelengths where one sounds above the cloud tops. This observation indicates temporal stability for the thermal structure, which consists of an approximate isothermal profile above the clouds at $68 \mathrm{~km}$ up to at least $74 \mathrm{~km}$.

Acknowledgements. We would like to thank J. Lecacheux and F. Colas for their kind help and expertise preparing Fig. 1

\section{References}

Carlson, R. W., Baines, K. H., Encrenaz, Th., Taylor, F. W., Drossart, P., Kamp, L. W., Pollack, J. B., Lellouch, E., Collard, A. D., Callcutt, S. B., Grinspoon, D. H., Weissman, P. R., Smythe, W. D., Ocampo, A. C., Danielson, G. E., Fanale, F. P., Johnson, T. V., Kieffer, H. H., Matson, D. L.., McCord, T. B. and Soderblom, L. A., Galileo infrared imaging spectroscope measurements at Venus. Science' 253, 1541 1548,1991 .

Diner, D. J.. The equatorial and polax limb-darkening of Venus in the $8-20 \mu \mathrm{m}$ region. J. Atmos. Sci. 35, 2356-2361, 1978.

Dubois, R., Zasova, L. V., Spränkuch, D., Moroz, V. I., Schäfer, K., Ustinov, E. A., Oertel, D., Linkin, V. M., Döhler, W. and Güldner, J., Thermal structure of the middle atmosphere of Venus from Venera 15 data. Feröffentichnowen des Forschungshereid $\left.G e^{\prime \prime}\right)-$ und Kosmoswissenschafien. Heft 18. pp. 99.119 .1990

Grinspoon, D. H., Pollack, J. B., Sitton, B. R., Carlson, R. W., Kamp, L. W., Baines, K. H., Encrenaz, Th. and Taylor, F. W., Probing Venus's cloud structure with Galileo NIMS. Plan't. Space Sci. 41, 515-542, 1993.

Roos, M., Drossart, P., Encrenaz, Th., Lellouch, E., Bézard, B., Carlson, R. W., Baines, K. H., Kamp, L. W., Taylor, F. W., Collard, A. D., Calcutt, S. B., Pollack, J. B. and Grinspoon, D. H., The upper clouds of Venus : determination of the scale height from NIMS-Galileo infrared data. Planct. Space Sit. 41, 504 514, 1993 .

Roos-Serote, M., Drossart, P., Encrenaz, Th., Lellouch, E., Carlson, R. W., Baines, K. H., Taylor, F. W. and Calcutt, S. B., The thermal structure and dynamics of the atmosphere of Venus between 70 and $90 \mathrm{~km}$ from the Galileo-NIMS spectra. learus 114, 300 309. 1995.

Schubert, G., Atmosphere circulation and dynamical state, in l'ents (edited by D. M. Hunten et al.), pp. 681-765. University of Arizona Press, Tucson. Arizona, 1983.

Seiff, A., Thermal structure of the atmosphere of Venus, in lenus (edited by D. M. Hunten 't al.), pp. 215279 . University of Arizona Press. Tucson. Arizona, 1983.

Seiff, A., Schofield, J. T., Kliore, A. J., Taylor, F. W., Limaye, S. S., Revercomb, H. E., Sromovsky, L. A., Kerzhanovich, V. 
Y., Moroz, V. I. and Morov, M. Ya., Models of the structure of the atmosphere of Venus from the surface to 100 kilometer altitude. Adr. Space Ress. 5. $358,1985$.

Taylor, F. W., Beer, R., Chahine, M. T., Diner, D. J., Elson, L. S., Haskins, R. D.. McCleese, D. J., Markonchik, I. V.,
Reichley, P. E., Bradley, S. P., Delderfield, J., Schofield, J. T., Farmer, L. B., Froidevaux. I... Leung. J., Coffey, M. T. and Gille, J. C.. Structure and meteorology of the middle atmosphere of Venus : infrared remote sensing from the Pioncer Orhiter I. Cisophys. Re's. 85, 796? 8006. 1980. 